NASA Technical Memorandum 87198

\title{
Compensation of Reflector Surface Distortions Using Conjugate Field Matching
}

(NASA-TE-87198) COAPENSATICN OF BEFLECTOB

Roberto J. Acosta

Lewis Research Center Cleveland, Ohio

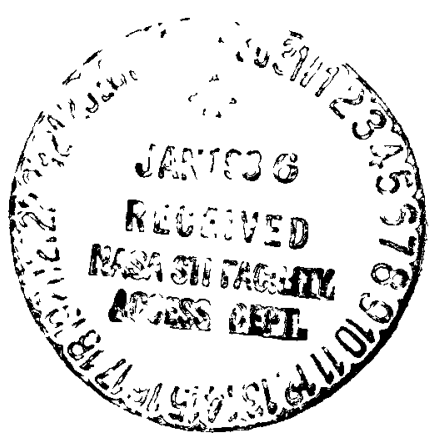

Prepared for the International IEEE A/P-S Symposium and National Radio Science Meeting Philadelphia, Pennsylvania, June 9-13, 1986 


\title{
COMPENSATION OF REFLECTOR SURFACE DISTORTIONS USING
}

\section{CONJUGATE FIELD MATCHING}

\author{
Roberto J. Acosta \\ National Aeronautics and Space Administration \\ Lewis Research Center \\ Cleveland, Ohio 44135
}

\begin{abstract}
The feasibility of compensating for reflector surface distortions has been investigated. The performance characteristics (gain, sidelobe level, null location, beamwidth, etc.) of space communication reflector antenna systems degrade as the reflector surface distorts due to thermal effects from a varying solar flux. The technique reported here will maintain the design radiation performance independently of thermal effects on the reflector surface. With the advent of monolithic microwave integrated circuits (MMIC), a greater flexibility in array-fed reflector system design can be achieved. MMIC arrays provide independent control of amplitude and phase for each of many radiating elements of the feed array. The conjugate field matching technique provides a basis for obtaining the required element excitations under surface distortion for maintaining the design radlation performance. It is assumed that the surface characteristics ( $x, y, z$, first derivatives, and second derivatives) under distortion are known.
\end{abstract}

\section{INTRODUCTION}

Array-fed reflector configurations are very desirable for space communication multibeam antenna systems. Much effort has been devoted to develop reflector materials and structural techniques for compensating thermal distortions. The compensating technique described here presents an alternate method for maintaining reflector antenna performance independently of thermal distortions. It requires independent amp litude and phase control of the feed array excitation. Such a requirement can be met with MMIC arrays. By using NASTRAN and SINDA (Ref. 1) computer programs to simulate thermal distortions, a basis for realistic antenna performance degradation can be established. For example, gain loss of 2 to $5 \mathrm{~dB}$, sidelobe level increase of $10 \mathrm{~dB}$, pointing loss of $7^{\circ}$ to $2^{\circ}$, etc., has been predicted by a NASTRAN-SINDA simulation of thermal distortions on offset reflector antennas. Sinusoidal systematic distortions were used for demonstrating the compensation technique.

\section{ANALYSIS AND RESULTS}

Given the desired antenna performance and reflector surface characteristics ( $x, y, z$, first derivatives, second derivatives), the problem involving surface distortions can be described as follows: To determine the minimum number of array elements, their best location and their excitations that will give rise to the desired antenna performance. The reflector surface can be distorted (compensation problem) or it can be 
undistorted (design problem). Figure 1 presents a graphical description of the compensation problem. It is assumed that a design has already been established (array feed characteristics are known). Figure 2 shows the general approach taken for solving the compensation problem. The antenna performance characteristics (gain, sidelobe level, beamwidth, null location, etc.) can be described by the far-zone electric field or by the aperature field distribution. Notice that the far-zone electric fleld and the aperature field distribution are a Fourier transform pair (Ref. 2).

The focal plane distribution contains the necessary information for obtaining the required number of elements, their location, and their proper complex excitations. Two methods can be used to obtain the focal plane distribution: (1) geometrical theory of diffraction (GTD) (Ref. 3), and (2) physical optics (PO) (Ref. 4). Conceptually the desired aperture field distribution (antenna performance) can be thought of as weighted (tapered) plane wave incident on the reflector surface from a prescribed observation direction. Using this concept, the fields in the focal plane can be calculated from the reflected and diffracted. fields on the reflector surface. By taking the complex conjugate of the fields in the focal plane, the complex element excitation are obtained (conjugate field matching (Refs. 5 to 9 )).

The configuration used for demonstrating the compensation technique is presented in Fig. 3. A sinusoidal type distortion was used to simulate the distorted surface. Table I presented the design and distortion parameters used as inputs by the computer program. Figure 4(a) shows the desired design (undistorted) antenna performance. With the distorted parameters in Table I, the resultant antenna performance degrades to that shown in Fig. 4(b). If this were a real case, the performance shown (Fig. 4(b)) would not be acceptable when compared to the undistorted case (Fig. 4(a)). Using GTD and the compensation approach summarized in $\mathrm{Fig} .2$, the obtained compensated antenna performance is shown in Fig. $4(\mathrm{c})$. The compensated antenna performance is not exactly like the undistorted (Fig. $4(\mathrm{a})$ ) but all performance characteristics were within an acceptable range. More radiating elements are needed in order to improve further the compensated antenna performance.

\section{REFERENCES}

1. R.E. Steinbach and S.R. Winegar, "Interdisciplinary Design Analysis of a Precision Spacecraft Antenna," in Structures, Structural Dynamics and Materials Conference, 26th, Part 1, AIAA, 1985, pp. 704-712.

2. R.E. Collin and F.J. Zucker, Antenna Theory. New York: McGraw-Hill, 1969, Chap. 3, pp. 66-68.

3. P.T.C. Lam, S.W. Lee, and R. Acosta, "Secondary Pattern Computation of an Arbitrarily Shaped Main Reflector," NASA TM-87162, 1985. 
4. Y. Rahmat-Samii and V. Galindo-Israel, "Shaped Reflector Antenna Analysis Using the Jacobi-Bessel Series," IEEE Trans. Antennas and Propag., Vol. AP-28, pp. 425-435, 1980.

5. H.C. Minnett and B. Mac A. Thomas, "Fields in the Image Space of Symmetrical Focusing Reflectors," Proc. IEE, Vol. 115, Pp. 1419-1430, 1968.

6. C.C. Hung and R. Mittra, "Secondary Pattern and Focal Region Distribution of Reflector Antennas Under Wide-Angle Scanning," IEEE Trans. Antennas and Propag., Vol. AP-31, pp. 756-763, 1983.

7. W.H. Watson, "The Field Distribution in the Focal Plane of a Paraboloidal Reflector," IEEE Trans. Antennas and Propag., Vol. AP-12, pp. 561-569, 1964.

8. A.V. Mrstik and P.G. Smith, "Scanning Capabilities of Large Parabolic Cylinder Reflector Antennas with Phased-Array Feeds," IEEE Trans. and Antennas Propag., Vol. AP-29, pp. 455-462, 1981.

9. P.T. Lam, S.W. Lee, D.C.D. Chang, and K.C. Lang, "Directivity Optimization of a Reflector Antenna with Cluster Feeds: A Closed-Form Solution," IEEE Trans. on Antennas and Propagation, Vol. AP-33, Nov. 1985. 
TABLE I. - DESIGN AND DIS-

TORTION PARAMETERS

\begin{tabular}{|lr|}
\hline Computer simulation & $2-0$ \\
Frequency, GHz & 60 \\
Element spacing & $\lambda / 2$ \\
Number of elements & 16 \\
Y-polarized feeds & --- \\
Sinusoidal distortion & - \\
Number of cycles & 1.5 \\
Peak deviation, $\Delta$ & $\lambda / 20$ \\
\hline
\end{tabular}




\section{PROBLEM DESCRIPTION}
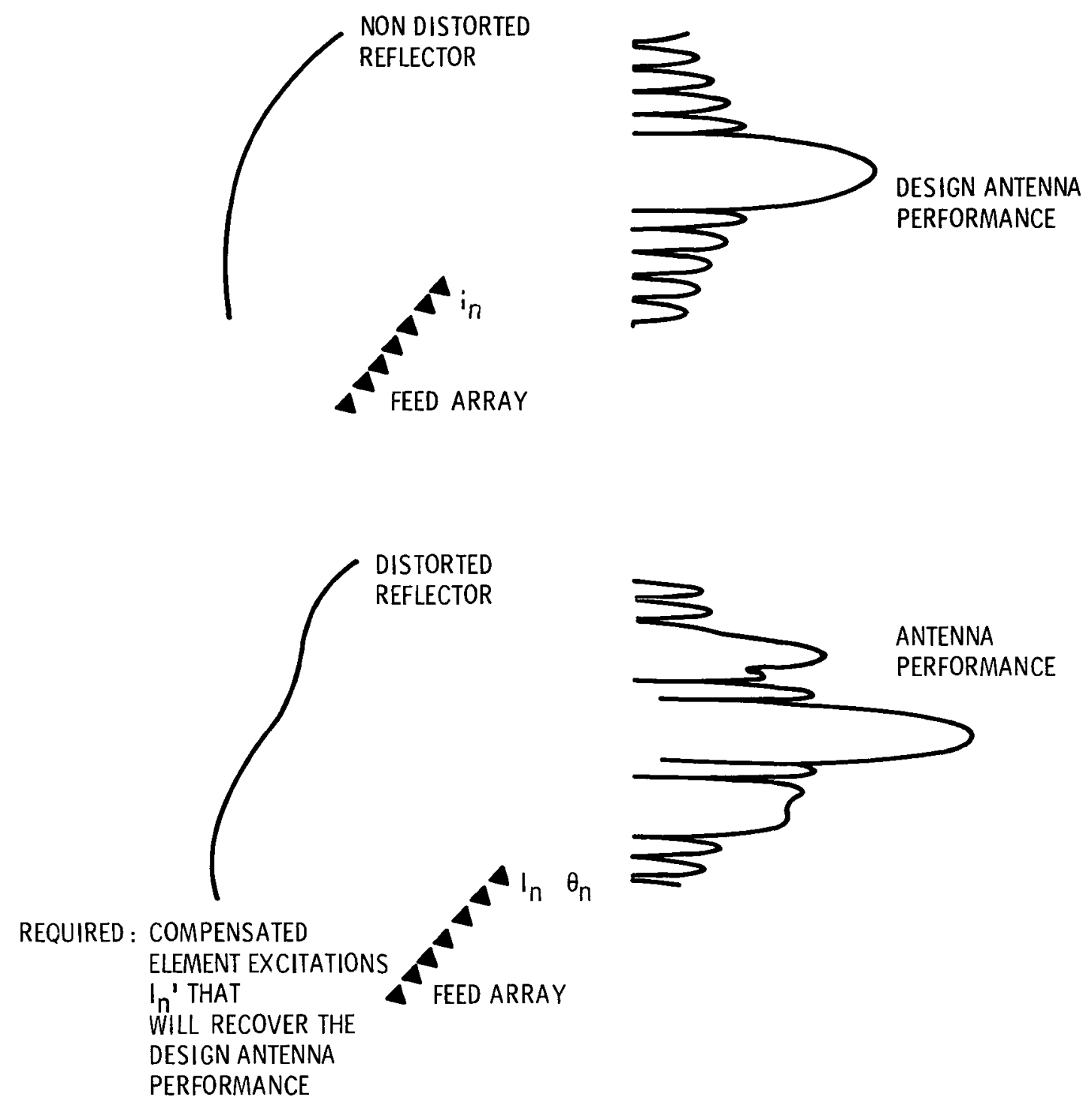

Figure 1. - The distorted antenna problem. 


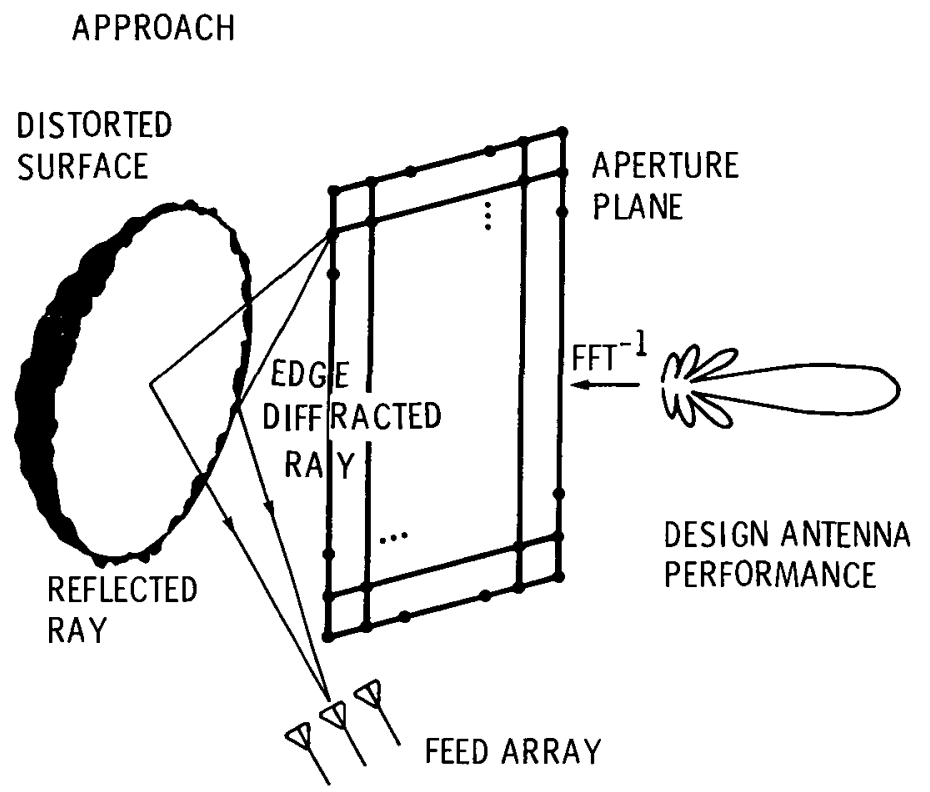

Figure 2. - General approach for solving the compensation problem.

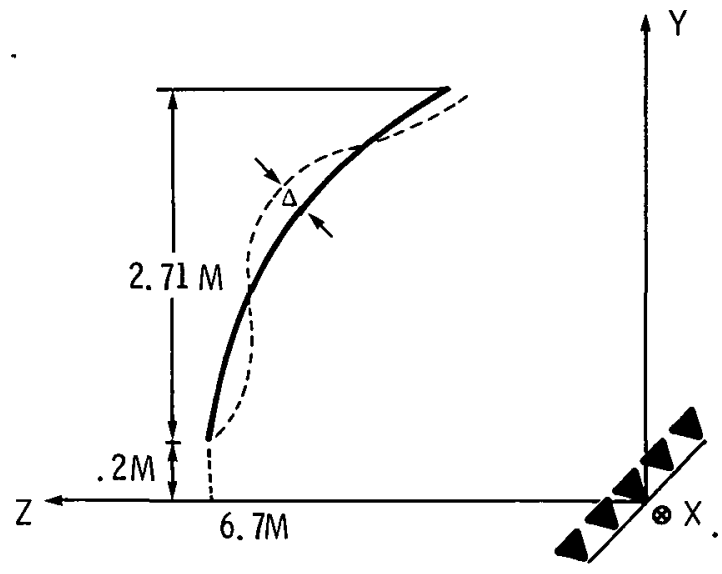

Figure 3. - Reflector configuration. 


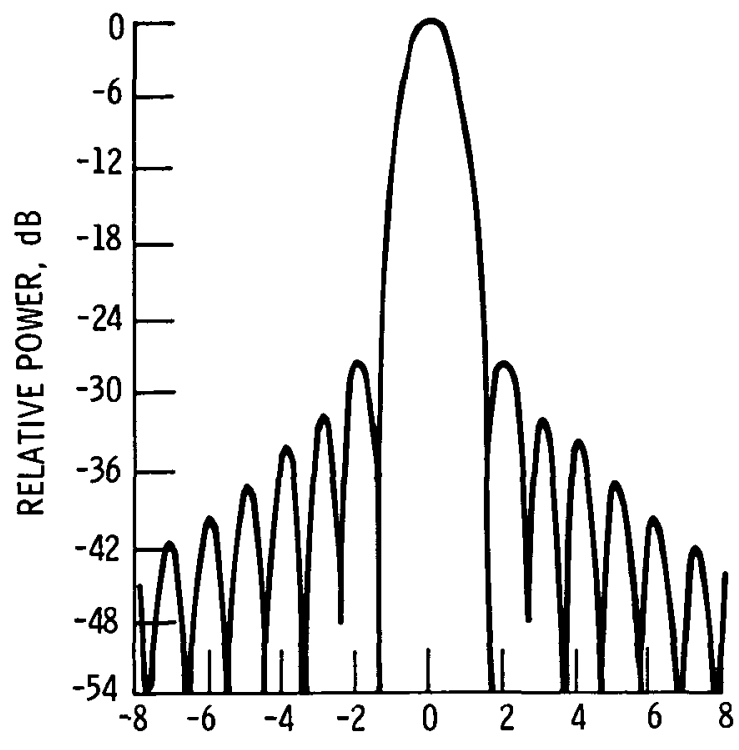

(a) Design (undistorted).

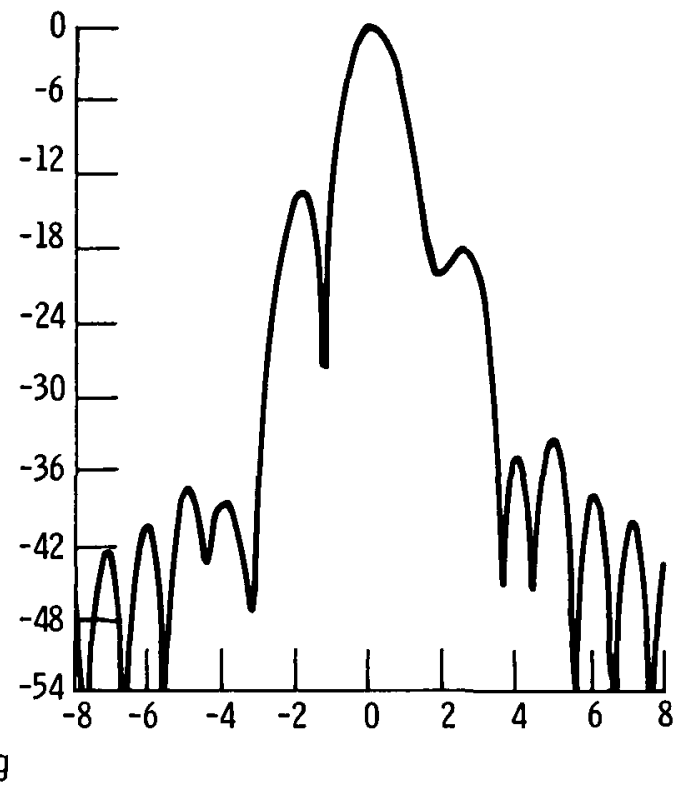

(b) Distorted.

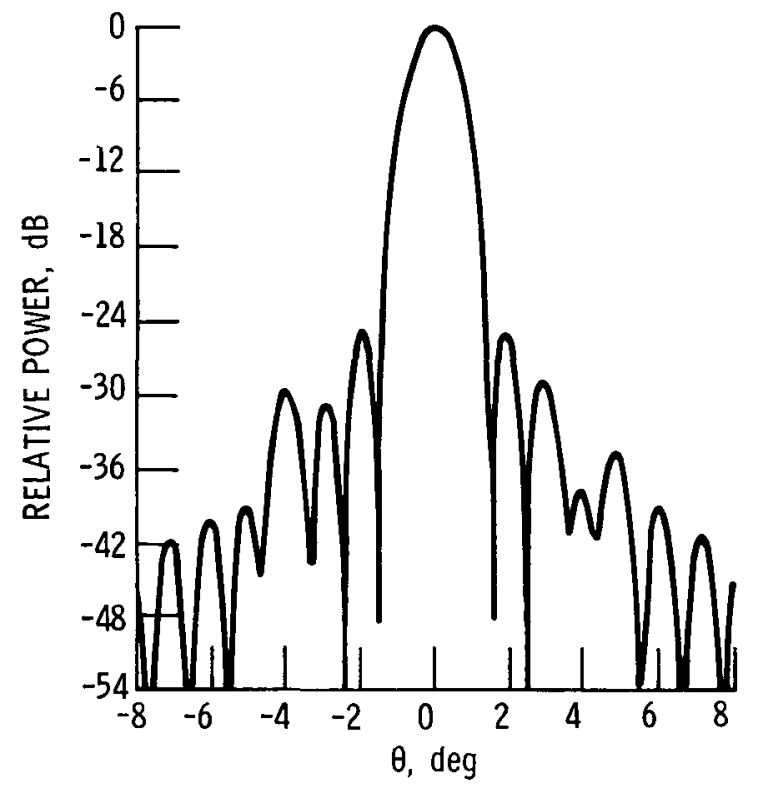

(c) Compensated.

Figure 4. - Antenna performance. 


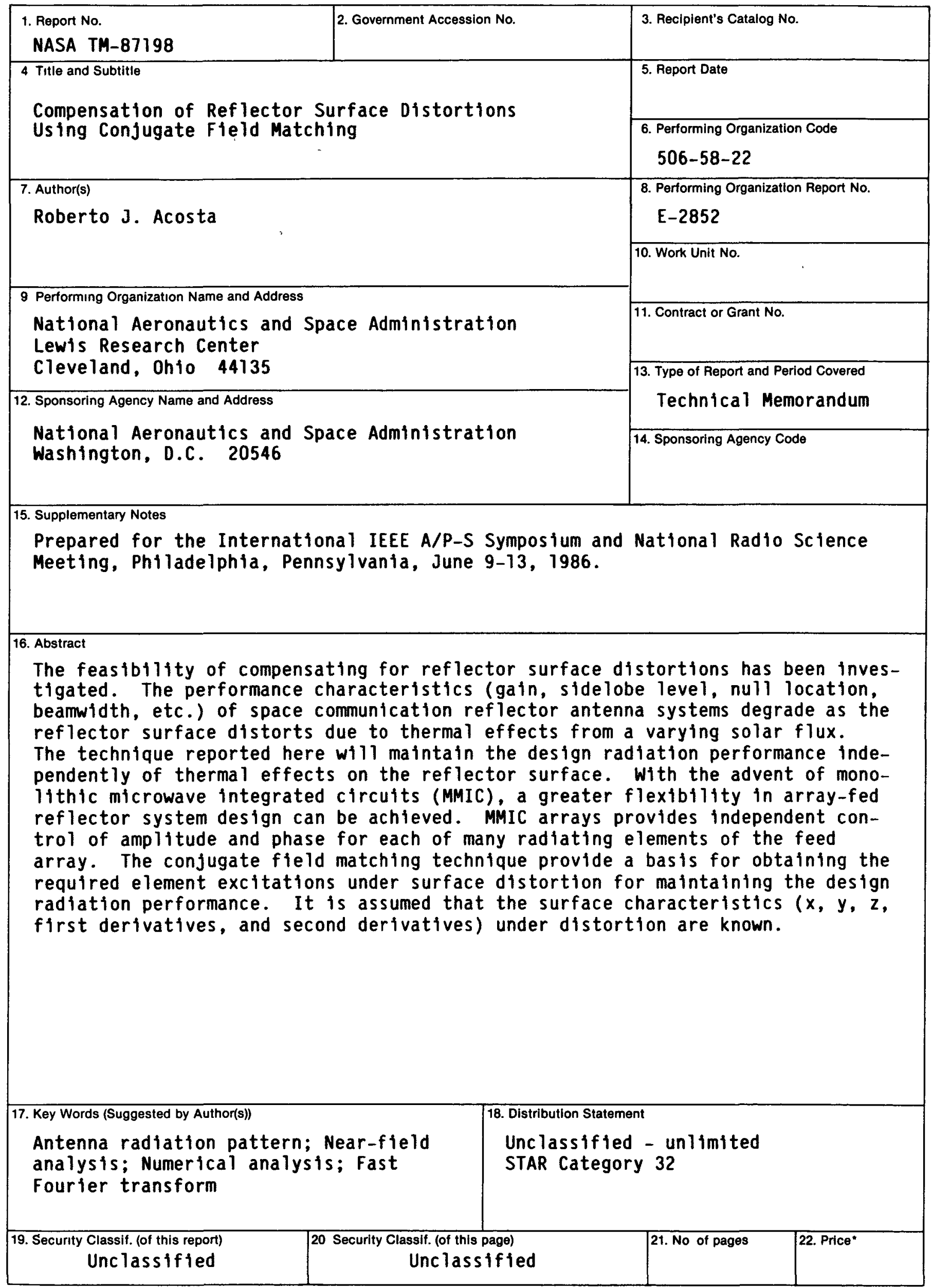

*For sale by the National Technical Informatıon Service, Springfield, Vırginia 22161 
Natıonal Aeronautics and Space Administratıon

Lewis Research Center

Cieveland Ohı 44135

Official Businoss

Penally for Private Use $\$ 300$
SECOND CLASS MAIL

ADDRESS CORRECTION REQUESTED

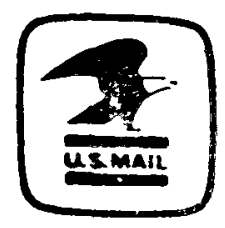

Postage and Fees Pa:d National Aeronautics and Space Admin.strat on IJASA-451 